\title{
AC 2010-652: INFLUENCES AND INTERESTS IN HUMANITARIAN ENGINEERING
}

\section{Christina White, Columbia University}

Richard Crawford, University of Texas at Austin

Kris Wood, University of Texas

Austin Talley, University of Texas, Austin 


\title{
Interests and Influences in Humanitarian Engineering
}

\author{
Motivation \\ It is ironic that the engineering fields, which design and build bridges, are the areas where we \\ have one of the weakest bridges in closing the accessibility, achievement, and equity gaps \\ between genders and ethnicities. In 1950, the U.S. Congress established the National Science \\ Foundation (NSF) with the mission "to initiate and support... engineering.... and science \\ education programs at all levels"1; yet, half a century later, problems of access, achievement, and \\ equity for females and ethnic minorities in these fields remain, resulting in a lack of diversity in \\ engineering ${ }^{2-3}$.
}

\section{Overview}

In this paper, we consider a study with the goal of obtaining insights into diversity issues, including potential approaches for addressing diversity inequity ${ }^{4-14}$ (Fig. 1). This multiplemethods study is comprised of a survey of participants whose primary composition is as higher education students currently studying engineering. The multi-question survey gathers anonymous demographic information and relative interests in humanitarian engineering experiences from 110 persons which consist of different ethnicities. These participants respond to multiple choice, short answer, and essay questions. The data are aggregated to represent all respondents and then disaggregated to look for trends only focusing on women and then also as trends only in students that are ethnic minorities. The data from both genders and varying ethnicities creates a more descriptive landscape of Humanitarian Engineering Experiences and Design (HEED), who participates in HEED, why they participate, and how they perceive their activeness with HEED.

Based on our study, a cacophony of voices resonates through narrative texts and survey responses to create a symphony about humanitarian engineering. Indeed, the inquiries in the survey are structured to finesse out factors influencing choices to pursue engineering, prioritize categories to describe humanitarian engineering, level of interest and participation in humanitarian engineering, and investigate thinking about engineering experiences as a sense of agency and as community development. The results of this survey provide insight into awareness of humanitarian engineering across various learning environments. Our data indicate that a large portion of females and males are attracted to humanitarian projects. The data also suggest that humanitarian engineering experiences are interesting pursuits and attracters for students that are ethnic minorities. These important results sculpt our understandings about ways to attract and retain a diverse group of engineers. 


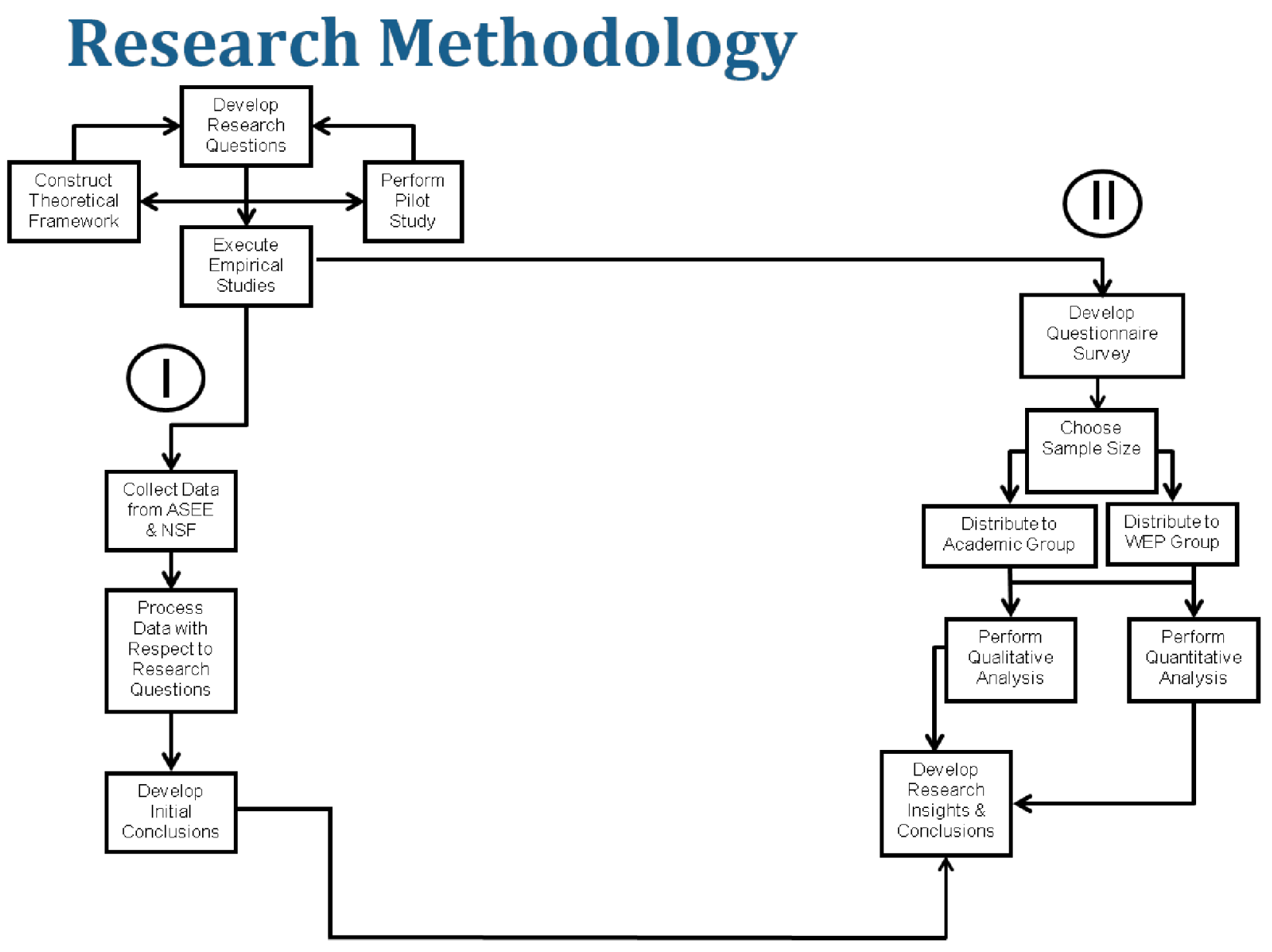

Figure 1. Research Methodology

As United States and world citizens, we all face issues and problems involving science including those pertaining to the energy, education, water, and shelter. Humanitarian engineering experiences can provide people with some of the tools to responsibly address these pressing problems. The Science, Technology, Society, and the Environment education movement encompasses humanitarian engineering and was first introduced in the 1970s after social movements of the 1960s and 1970s called for a change in science to include society, politics, and the idea of responsible citizenship ${ }^{2}$. We continue to face critical issues regarding the limited essential resources (i.e., energy, education, water, and shelter) available to some people that notably impact and perpetuate inequities in educational experiences and opportunities in life. Among the many who face inequities, millions of females contend with considerable challenges due to limited essential resources that humanitarian engineering addresses in an effort to promote democracy and social justice for citizens of our world. 
America's $44^{\text {th }}$ President Obama in his visionary inaugural speech urges us as American and world citizens to

... summon a new spirit of patriotism, of responsibility where each of us resolves to pitch in and work harder to not only look after ourselves but each other.... We will build the roads and bridges, the electric grids and digital lines that feed our commerce and bind us together. We will restore science to its rightful place, and wield technology's wonders to raise health care's quality and lower its cost. We will harness the sun and the winds and the soil to fuel our cars and run our factories. And we will transform our schools and colleges and universities to meet the demands of a new age. All this we can do. And all this we will do. ... For they have forgotten what this country has already done; what free men and women can achieve when imagination is joined to common purpose, and necessity to courage.... That as the world grows smaller, our common humanity shall reveal itself; and that America must play its role in ushering a new era of peace.... To the people of poor nations, we pledge to work alongside you to make your farms flourish and let clean waters flow to nourish starved bodies and feed hungry minds.

From drinking straws that protect against waterborne diseases to solar-powered incubators to assistive educational technology to environmentally-safe temporary housing for hurricane survivors, humanitarian engineering experiences and designs are prime examples of interventions which act locally to create possibilities of life-changing opportunities by: (a) breaking cycles of poverty and inequities through education, (b) ameliorating detrimental health conditions and addressing issues of limited food and access to clean water, (c) creating alternatives to inadequate shelter, (d) and reconsidering innovative alternatives for deficient energy conditions all of which citizens of the world have endured for hundreds of years. In this study, we investigate the interest and influences in undergraduate and graduate engineering students in pursuing humanitarian engineering.

\section{HEED Survey}

The 10-question survey [Appendix A] of 110 participants provides insight into questions, methods, and perceptions about factors influencing engineering education and HEED. The survey questions are a combination of short answer and multiple choice that provide qualitative and quantitative results. The survey participants are undergraduate and graduate engineering students at a prominent research university. Although in engineering fields the gender proportions are largely disproportionately White and male, we include data that represents a population that includes more women than are statistically in engineering. Indeed, 40:110 are women and 37:110 are non-White. The data from men and women as well as a representation of many ethnicities will create a more descriptive landscape of engineering education. Because of the possibilities to disaggregate the data in multiple ways, there are meaningful opportunities to interpret and discuss HEED so that this data can be a strong part of the mortar paving pathways to understanding engineering education. 
First, it is important to glean if students are even interested in humanitarian engineering [Fig. 1] and if so, of what value they believe it could be to the improvement of the world [Fig. 2].

Regardng your engagement in humanitarian engineering projects, please choose all that apply.

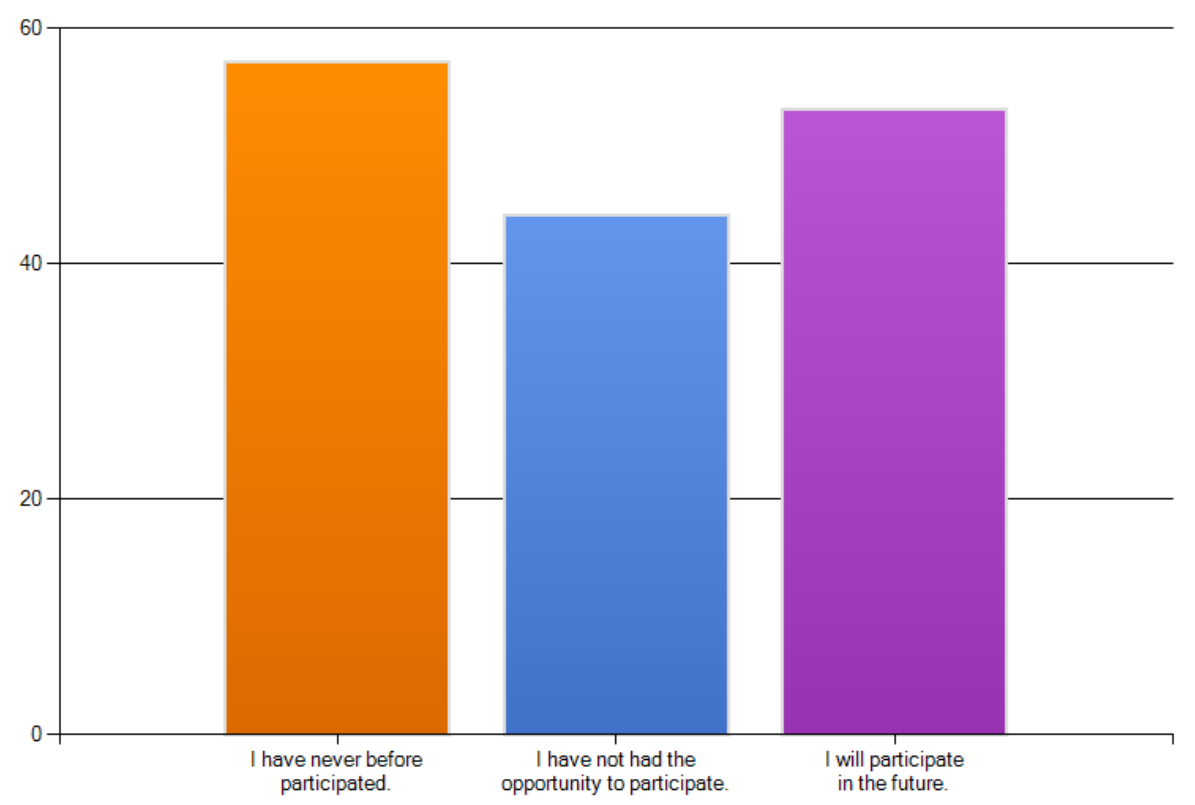

Figure 1. Results of Participation of HEED Projects

Are humanitarian engineering projects necessary to improve our world?

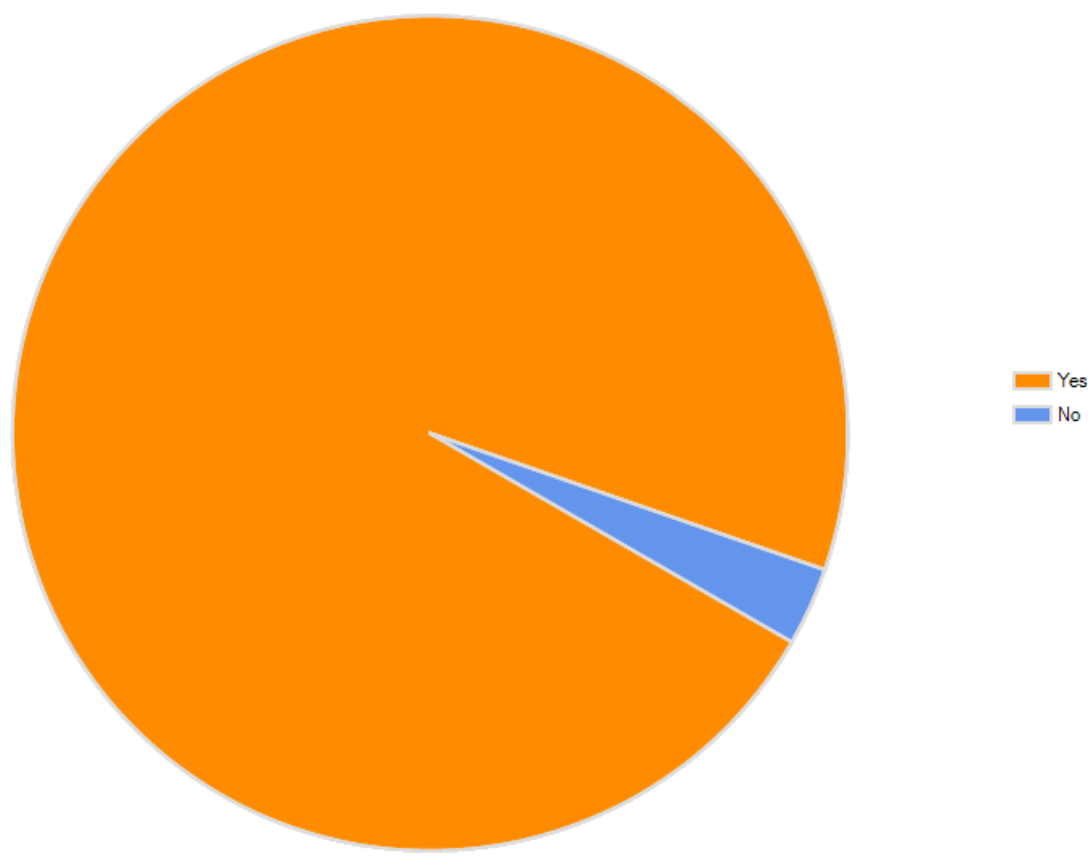

Figure 2. Results of Necessity of HEED Projects 
It is not surprising, but disappointing, that almost $60 \%$ of the participants have never before participated in HEED. In these results, it is also of interest over $40 \%$ state that they have not had the opportunity to participate. It would be beneficial to find out what people consider opportunities to participate including barriers to those perceived opportunities and also what connotes participation. Finally, we are hopeful at the statistics that show half of the group will participate in the future. When disaggregated, note that more than $2 / 3$ of women in choose to participate in the future. Results also indicate that almost $100 \%$ of the participants believe that humanitarian engineering will improve the world.

One of the survey questions is to glean information about the interdisciplinary nature of learning and practicing engineering [Figure 3]. This goes back to our previously stated assumptions of the interconnectivity of learning experiences, engineering for this study specifically. The responses to this question show that all of the participants rank Education as the most highly significant influence to humanitarian engineering. Technology, Medicine, Business, Economics, and Architecture are also ranked as highly significant. Language Arts and Kinesiology followed in the ratings as being significant to Humanitarian Engineering whereas Fine Arts, Philosophy, Gender Issues, and Pop Culture Media represent topics that are of neutral significance. When disaggregated, results differ in that women find Diversity Studies, Psychology, Business, and Pop Culture Media to be more significant to humanitarian engineering. This is interesting in that curricula can include interdisciplinary strands of these topics woven together with engineering as a means to attract and connect some of the female students to engineering education.

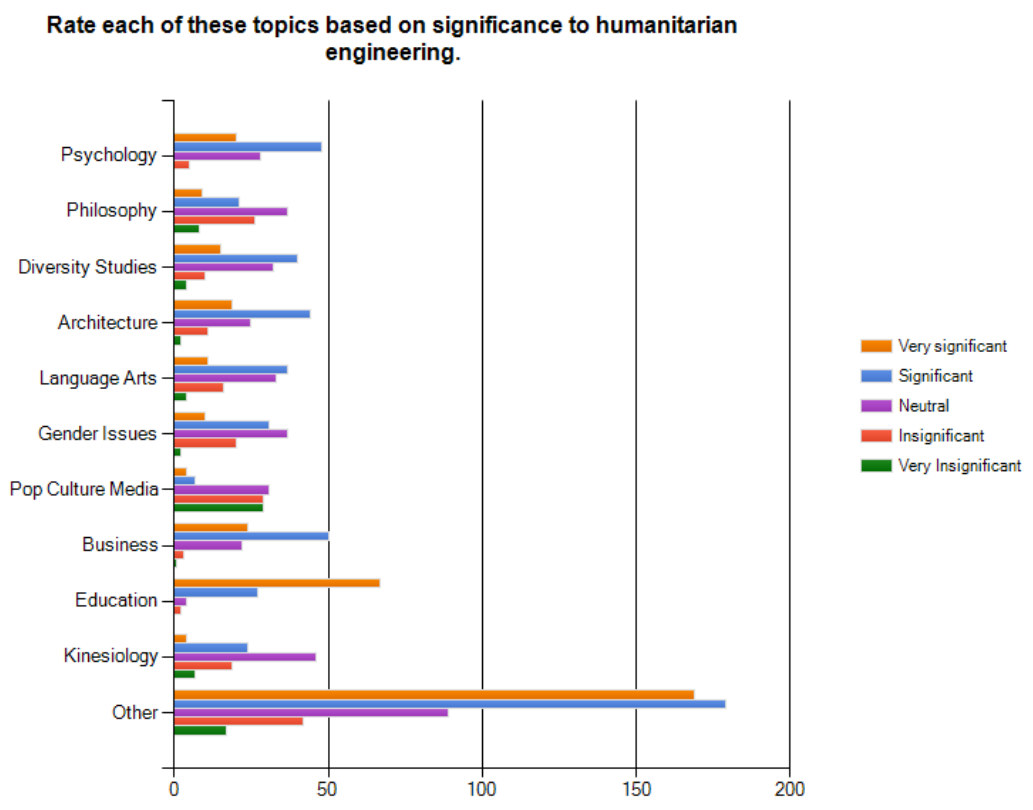

Figure 3. Interdisciplinary Topics 
The factors listed in the following question comes from Eccles' Expectancy Value theory and themes generated from other key studies in the review of literature about influences in pursuing engineering [Figure 5]. The survey reinforces the depth of findings of the literature review and key factors for conceptual structuring of this study. The Expectancy Value theory is a prominent, positivistic, motivational theory derived from a 30-year study. It suggests that we can explain learners' perceptions, expectations for success, decision-making, and external factors influencing their beliefs about academic fields and ability ${ }^{4-14}$.

Eccles's Expectancy Value theory suggests that a learner's persistence in, choice of, and performance in educational experiences can be predicted by her or his expectations for success (or perceptions of ability) and her or his perceptions of the value of each task or experience. The theory predicts that a learner's perceptions of ability in an educational experience and the values she or he attaches to an educational experience are influenced by her or his long and short-term goals and estimates of the difficulty of the subject. These beliefs, in turn, are influenced by the person's interpretation of past experiences of success and failure (attributions), perceptions of others' expectations, such as parents and peers, and perceptions of the gender stereotypes of the subject. This theory is useful for educators as we unpack antecedents to students' ways of knowing and deciding. It contains important and meaningful factors that have been and should continue to be included in discourses around how and why a choice is made to pursue an educational experience. A few other categories are included based on the review of literature that suggested alternative factors that are highly influential in pursuing engineering.

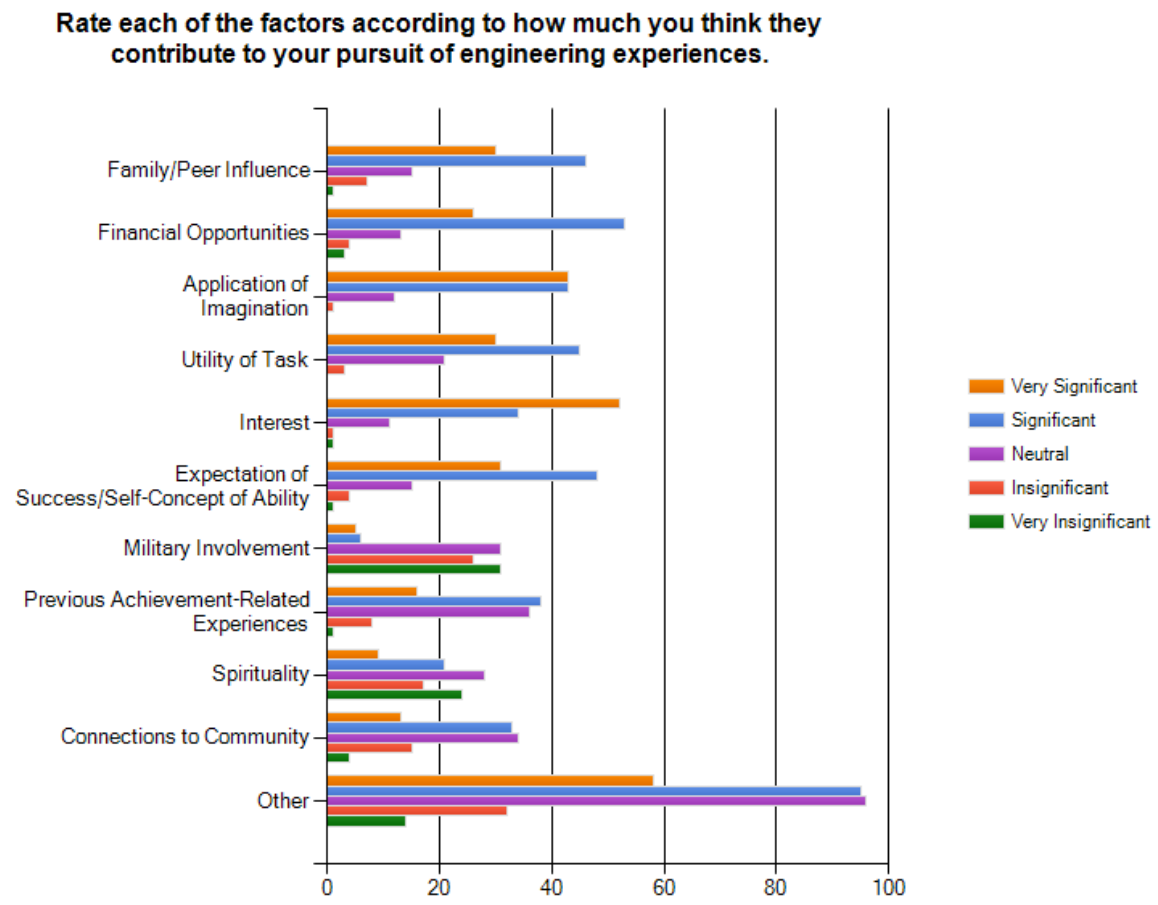

Figure 5. Influential Factors

In our survey results, we see that interest, application of imagination, expectation of success, and utility of task rank as being the most significant to those pursuing engineering. Each of these is 
also listed in the Expectancy Value theory except for imagination. This is of particular interest because often we find that imagination is left out of the educational system and the research around engineering education yet it is of great importance ${ }^{15}$. It is also of interest that military involvement is the least significant influence. At times, examples and advertisements to attract future engineers relate to military purposes ${ }^{11-12}$. Perhaps media and education examples should place less emphasis on military involvement with engineering to attract and retain more students who find connections with other factors instead.

\section{Qualitative Survey}

One analysis of this qualitative portion of the survey is in looking across the cumulative data of the three qualitative questions that are coded in NVivo8. This is with the intent to obtain the participants' perspectives on HEED in their own words ${ }^{16-18}$. This data represent themes across genders and ethnicities that have the highest frequency: community (including cultural milieu), water, shelter, and education. In this data, we zoom in to capture views of these main themes in the women's responses.

In line with the theoretical framework of this research, it is important to capture the participants in their own words. From "seeing the effect of natural disasters" to "studying abroad" and from "world economy" to "being a follower of Jesus", participants explain the influential factors influencing their future practice as an engineer in the first qualitative question. Women appear to be influenced highly in their engineering goals by their families. Travel and culture, working with kids, and involvement in their community are also salient factors influencing their notions of working with engineering. Over $35 \%$ of the women surveyed stated that working with kids or some form of teaching would affect their futures in engineering, and over $30 \%$ stated that their families have made an impact on their career choices. For example, one female participant stated that "conversations with my family" influences her future practice as an engineer. If more opportunities were made available to women in these interest fields, including more study abroad opportunities and more humanitarian engineering efforts, women might become more interested in the fields of engineering to make an impact on their communities.

Natural disasters are significant problems for people worldwide - the motivation for the second qualitative question. In response to it, each participant describes priority engineering problems to address in a hurricane that creates significant initial problems and which are in turn compounded by a number of subsequent problems, such as water borne disease. Most women in this survey addressed the basic necessities of survival first in their analysis of the subsequent problems resulting from a hurricane disaster. Food, water, shelter, medical attention, and clearing roads were mentioned by almost every responder. When faced with a series of problems caused by a hurricane, they addressed the most necessary problems of survival, along with some more long term goals like issues of the education system, infrastructure, and national aid.

Participants indicate that "helping senior citizens and disabled people get help because this section of the population is dependent on others for helping them", "lawlessness", and "emotional distress" are priorities for engineers to consider. These may not initially be what come to mind when thinking about engineering priorities in a natural disaster. This is especially intriguing and leads to better understanding the influence of cultural milieu on engineering experiences. 
The final qualitative question prompts respondents to include their perspectives about the ways that engineers can address the challenges facing developing countries. A range of ideas from "cheap and clean water supplies" to "develop biodegradable but safe waste containers to help prevent the spread of disease" to "helping anticipate changes that may arise as the country develops" are embedded in the survey results. These responses fell within larger categories that one might anticipate such as energy and transportation. The most interesting insight from this portion of the survey can actually be exemplified by the aforementioned comment, "helping anticipate changes that may arise as the country develops".

\section{Recommending Engineering Educators Take HEED}

This is an appealing quote to highlight in that it speaks for a larger population and important message of the present and future of engineering education. Indeed, engineers need to lend their strong abilities as problem solvers to anticipate changes that may arise as all countries in the world develop in this new millennium. Recalling Obama's inaugural speech, in part at the beginning of this work, we must "meet the demands of a new era". In this new era, a record high number of higher education students are involved in service learning. To better understand our developing world in the new millennium, a leading cadre from the National Academy of Engineers describes the 14 grand challenges that we face as world citizens. The 14 grand challenges combine engineering experiences in the context of social responsibility. The overall responses in the quantitative and qualitative portions of this research indicate that humanitarian engineering experiences like the grand challenges can connect to students across gender and ethnicities. It may behoove schools to tap into the momentum of increased service learning in conjunction with humanitarian engineering education to engage diverse students. Understanding that the grand challenges and applying them as frameworks for curriculum development is a key way to integrate disciplines and enrich STEM literacy skills. Curriculum development under the framework of these grand challenges provides opportunities for students to engage in long-term projects across disciplines and also provides a university-wide forum for professors to collaborate on projects. Engineering educators must listen to the call of students who now more than ever engage in service-learning activities and have a heightened awareness of a global issues directly relating to the grand challenges that we face in the $21^{\text {st }}$ century.

\section{References}

1. Suter, L. (1992). Indicators of science \& mathematics education in 1992. (Report No. NSF-93-95). Washington D.C.: National Science Foundation.

2. American Association for the Advancement of Science. (1989). Science for all Americans. New York: Oxford University Press.

3. Keller, E. (1985). Reflections on gender and science. New Haven: Yale University Press.

4. Anderson, L. \& Northwood, D. (2002). International Conference on Engineering Education: Recruitment and retention programs to increase diversity in engineering. Manchester, United Kingdom. Retrieved 6 December 2007 from http://www.ineer.org/Events/ICEE2002/Proceedings/Papers/Index/O065-O070/O069.pdf. 
5. Eccles, J.S. (2007). Where are all the women? Gender differences in participation in physical science and engineering. In S. J. Ceci \& W. M. Williams (Eds.), Why aren't more women in science? Top researchers debate the evidence (pp. 199-212). Washington, DC: American Psychological Association.

6. Eccles, J. S.(1994). Understanding women's educational and occupational choices Applying the Eccles et-al model of achievement-related choices. Psychology of Women Quarterly, 18, 585-609.

7. Felder, R. \& Brent, R. (2005). Understanding student differences. Journal of Engineering Education, 94, 57-72.

8. Felder, R. M., Felder, G. N., Mauney, M., Hamrin, C. E., \& Dietz, E. J. (1995). A longitudinal study of engineering student performance and retention. III. Gender differences in student performance and attitudes. Journal of Engineering Education, 84, $151-163$.

9. Eccles, J.S., Adler, T., Futterman, R., Goff, S., Kaczala, C., Meece, J., \& Midgley, C. (1983). Expectancies, values, and academic behaviors. In J. Spence (Ed.), Achievement and Achievement Motives (pp. 75-146). San Francisco: W.H. Freeman.

10. Rose, H. (1984). Is a feminist science possible? In (Ed.). Love, power, knowledge: Toward a feminist transformation of the sciences (pp. 25-48). Bloomington: Indiana University Press.

11. Haraway, D. (1991). Situated knowledges: The science question in feminism and the privilege of partial perspectives. In Simians, cyborgs and women: The Reinvention of nature (pp. 193-202). New York: Routledge.

12. Harding, S. (1991). Whose science? Whose knowledge? Thinking from women's lives. Ithaca, NY: Cornell University Press.

13. Jacobs, J. (1992). Women's learning styles and the teaching of mathematics. Math \& Science for Girls: A Symposium, 43-55.

14. Jacobs, J. \& Eccles, J. S. (1985). Gender differences in math ability: The impact of media reports on parents. Educational Researcher, 14, 20-25.

15. Bakhtin, M. (1981). The dialogic imagination. Austin, TX: The University of Texas Press.

16. Bogdan, R.C., \& Biklen, S.K. (2003). Qualitative research for education: An introduction to theories and methods ( $4^{\text {th }}$ ed.). Boston: Allyn and Bacon.

17. Clandinin, D. \& Connelly, F. (2000). Narrative inquiry: Experience and story in qualitative research. San Francisco: Jossey-Bass, Inc.

18. Denzin, N. \& Lincoln, Y. (2003). Collecting and interpreting qualitative materials. Thousand Oaks, CA: Sage Publications, Inc. 


\section{Appendix}

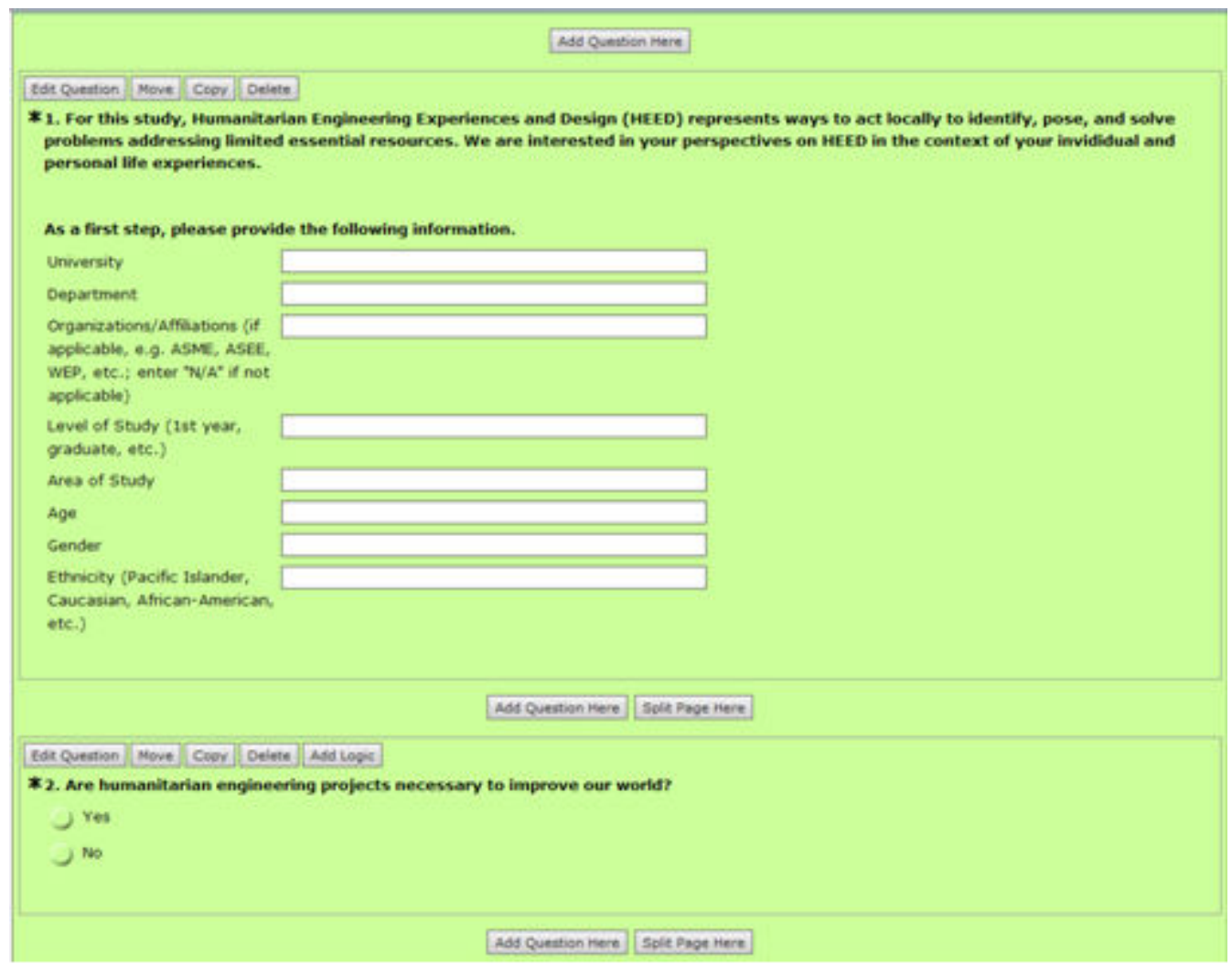

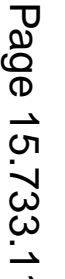


*3. Regardng your engagement in humanitarian engineering projects, please choose all that apply.

$\Gamma \mathrm{t}$ have never before participated.

I have not had the opportunity to participate.

I will participate in the future.

Add Question Here Solit Page Here

\begin{tabular}{|l|l|l|}
\hline Edrt Question Move Copy Delete & \\
\hline
\end{tabular}

*4. A large population has just been hit by a hurricane. The hurricane creates significant intial problems which are in turn compounded by a number of subsequent problems, such as water borne disease. People of the city face extreme challenges as they must address their basic human needs. From an engineering perspective, identify critical problems because of this natural disaster. Please use at least 3 specific examples in priority order.

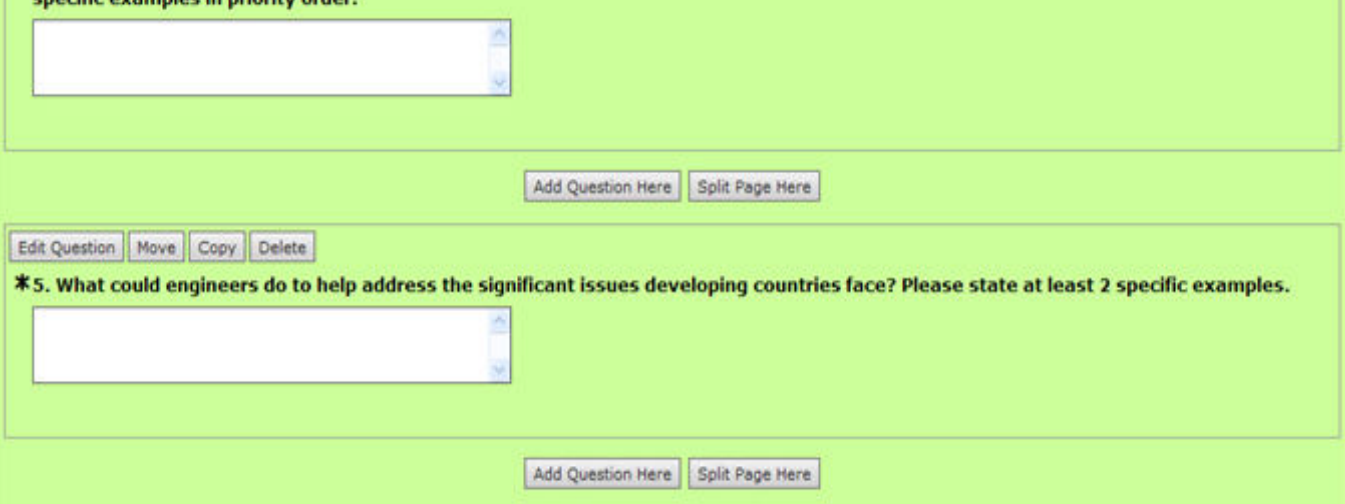

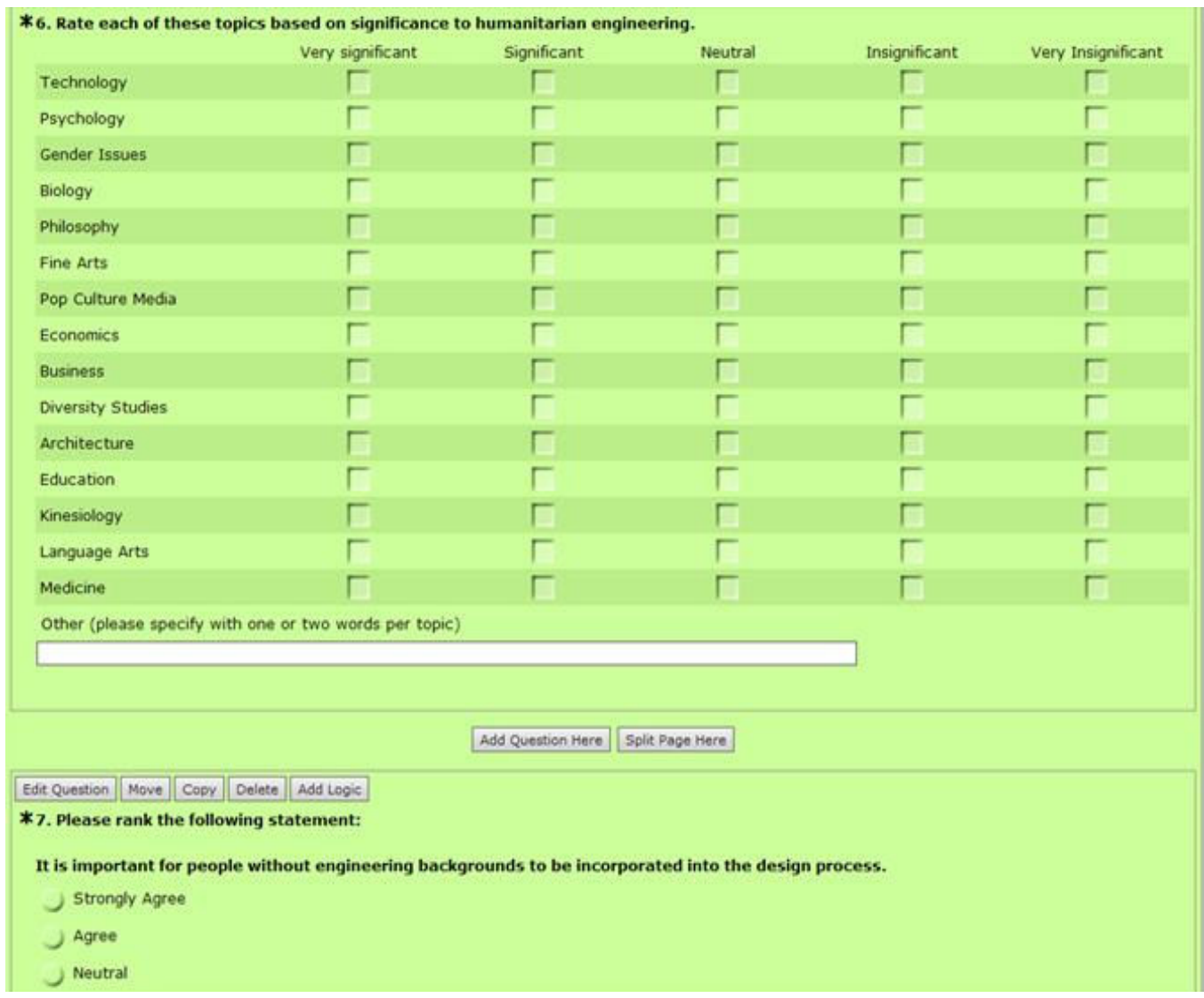




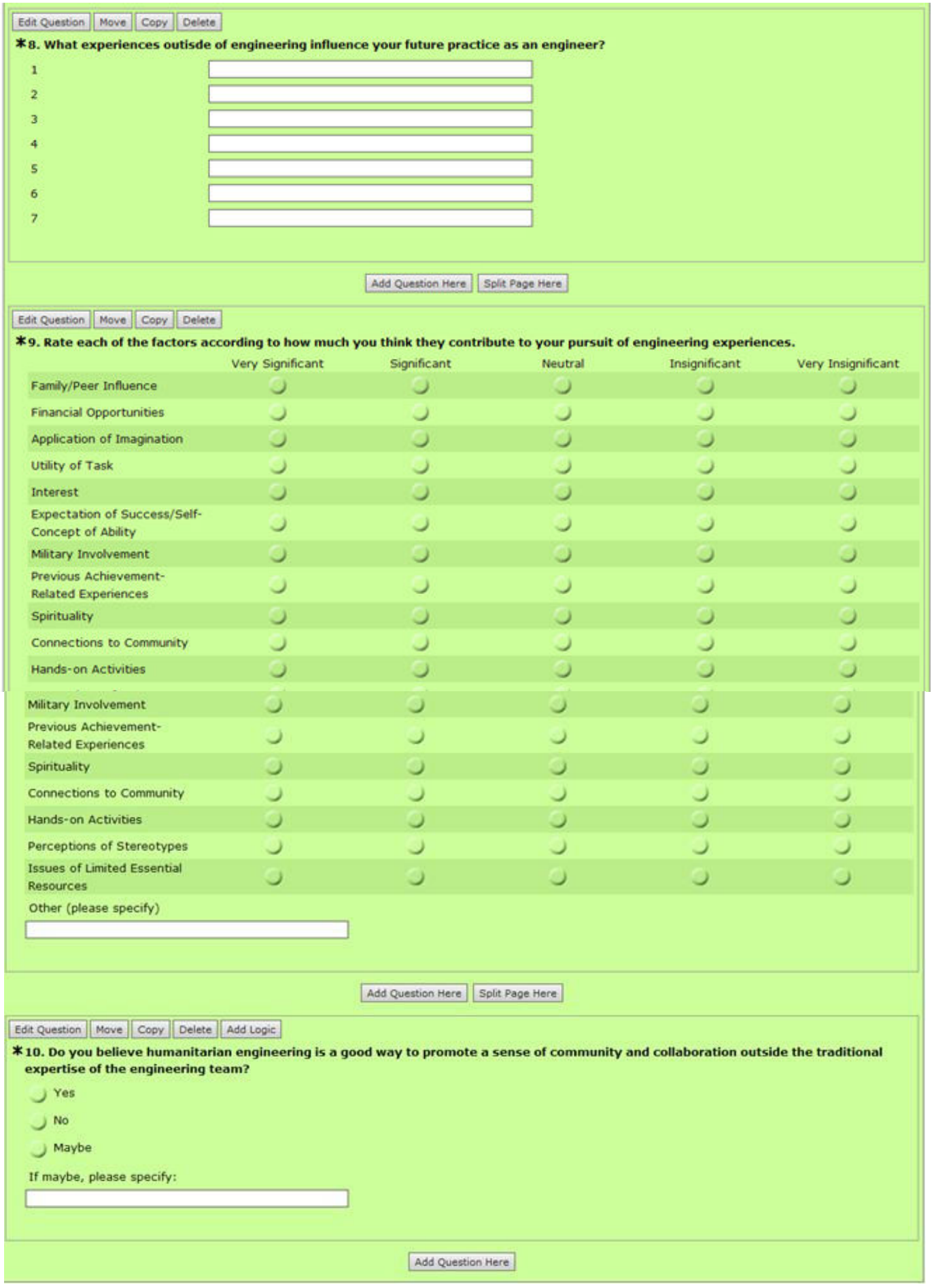

Appendix A. HEED Survey

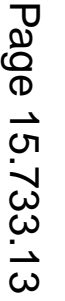

